\title{
Contextualizing the relevance of basic sciences: small-group simulation with debrief for first- and second-year medical students in an integrated curriculum
}

\author{
This article was published in the following Dove Press journal: \\ Advances in Medical Education and Practice \\ 18 January 2017 \\ Number of times this article has been viewed
}

\author{
Samara B Ginzburg' \\ Judith Brenner' \\ Michael Cassara ${ }^{2}$ \\ Thomas Kwiatkowski' \\ Joanne MWilley' \\ 'Department of Science Education, \\ Hofstra Northwell School of \\ Medicine, Hempstead, ${ }^{2}$ Department \\ of Emergency Medicine, Northwell \\ Health, Great Neck, NY, USA
}

Correspondence: Samara B Ginzburg Department of Science Education, Hofstra Northwell School of Medicine, 500 Hofstra University, Hempstead, NY II549, USA

$\mathrm{Tel}+|5| 6463750 \mid$

Fax + I $516463563 \mid$

Email Samara.Ginzburg@hofstra.edu
Aim: There has been a call for increased integration of basic and clinical sciences during preclinical years of undergraduate medical education. Despite the recognition that clinical simulation is an effective pedagogical tool, little has been reported on its use to demonstrate the relevance of basic science principles to the practice of clinical medicine. We hypothesized that simulation with an integrated science and clinical debrief used with early learners would illustrate the importance of basic science principles in clinical diagnosis and management of patients.

Methods: Small groups of first -and second-year medical students were engaged in a high-fidelity simulation followed by a comprehensive debrief facilitated by a basic scientist and clinician. Surveys including anchored and open-ended questions were distributed at the conclusion of each experience. Results: The majority of the students agreed that simulation followed by an integrated debrief illustrated the clinical relevance of basic sciences (mean \pm standard deviation: $93.8 \% \pm 2.9 \%$ of first-year medical students; $96.7 \% \pm 3.5 \%$ of second-year medical students) and its importance in patient care ( $92.8 \%$ of first-year medical students; $90.4 \%$ of second-year medical students). In a thematic analysis of open-ended responses, students felt that these experiences provided opportunities for direct application of scientific knowledge to diagnosis and treatment, improving student knowledge, simulating real-world experience, and developing clinical reasoning, all of which specifically helped them understand the clinical relevance of basic sciences.

Conclusion: Small-group simulation followed by a debrief that integrates basic and clinical sciences is an effective means of demonstrating the relationship between scientific fundamentals and patient care for early learners. As more medical schools embrace integrated curricula and seek opportunities for integration, our model is a novel approach that can be utilized.

Keywords: basic and clinical science integration, preclinical simulation, clinical reasoning simulation

\section{Introduction}

The prevalence of integrating the basic, clinical, and social sciences in undergraduate medical education (UME) curricula, as described by Kulasegaram et al $^{1}$ and Ginzburg et $\mathrm{ll}^{2}{ }^{2}$ is increasing. This reflects the recommendations of the Carnegie Foundation ${ }^{3}$ and the demonstration that integration of basic and clinical sciences improves diagnostic accuracy among preclinical students. ${ }^{4}$ However, when seeking to create integrated curricula, establishing the clinical relevance of the basic sciences for early learners remains a challenge. ${ }^{3,5}$ Among the variety of pedagogies that have been adopted to address this need, ${ }^{1}$ little attention has been paid to simulation in the preclinical years, despite the fact that simulation has been proposed to promote "translational scientific 
expertise" ${ }^{6}$ Given that $>90 \%$ of medical schools report the use of simulation, ${ }^{7}$ this presents an opportunity to leverage the power of simulation to address this problem.

Beginning in 2011, with the matriculation of our first class, we have regarded high-fidelity simulation as an opportunity to integrate basic and clinical sciences in a way in which students can experience the importance of each. The goal of the current pilot study was to determine whether small-group simulation exercises, anchored with extended post-simulation debriefs, were viewed by first- and secondyear medical students as a means to promote the clinical relevance of basic sciences learned in a fully integrated curriculum. $^{2}$

\section{Methods}

Student participants were enrolled in the first 2 years of our educational program, referred to as the First 100 Weeks, composed of six integrated courses (Figure 1). Each course included the following three curricular components: mechanisms of health, disease, and intervention (MHDI), structure, and patient, physician, and society (PPS). ${ }^{2}$ MHDI included physiology, pathophysiology, and therapeutics. Structure used both non-laboratory and laboratory formats to simultaneously integrate gross anatomy, histology, pathology, embryology, medical imaging, clinical reasoning, and physical diagnosis. PPS was composed of two components, classroom-based sessions tied to the School of Medicine's themes (communication, professionalism, and physical diagnostic skills) and drivers (continuum of care, decision making and uncertainty, social context/responsibility, quality and effectiveness, and scientific discovery), and the initial clinical experience in which students spent one half-day per week engaged in patient care in an ambulatory practice.

For a period of a year and a half, at the end of each integrated course (eight courses total), each class of 100 was divided into small groups of students $(n \leq 6)$ who participated in two simulations. In each simulation, students were required to work as a team to evaluate, manage, and treat a simulated patient with a specific chief complaint and an underlying diagnosis related to recent coursework. Upon entering a room with a high-fidelity simulation mannequin, three teammates were charged with discerning the patient's chief complaint, assessing vital signs, gathering a history, doing a physical examination, ordering diagnostic tests, interpreting test results, and implementing management to stabilize the patient. The other three teammates observed

\section{Curriculum Overview: The First 100 Weeks}

HOFSTRA NORTHWELL

AT HOFSTRA UNIVERSITY
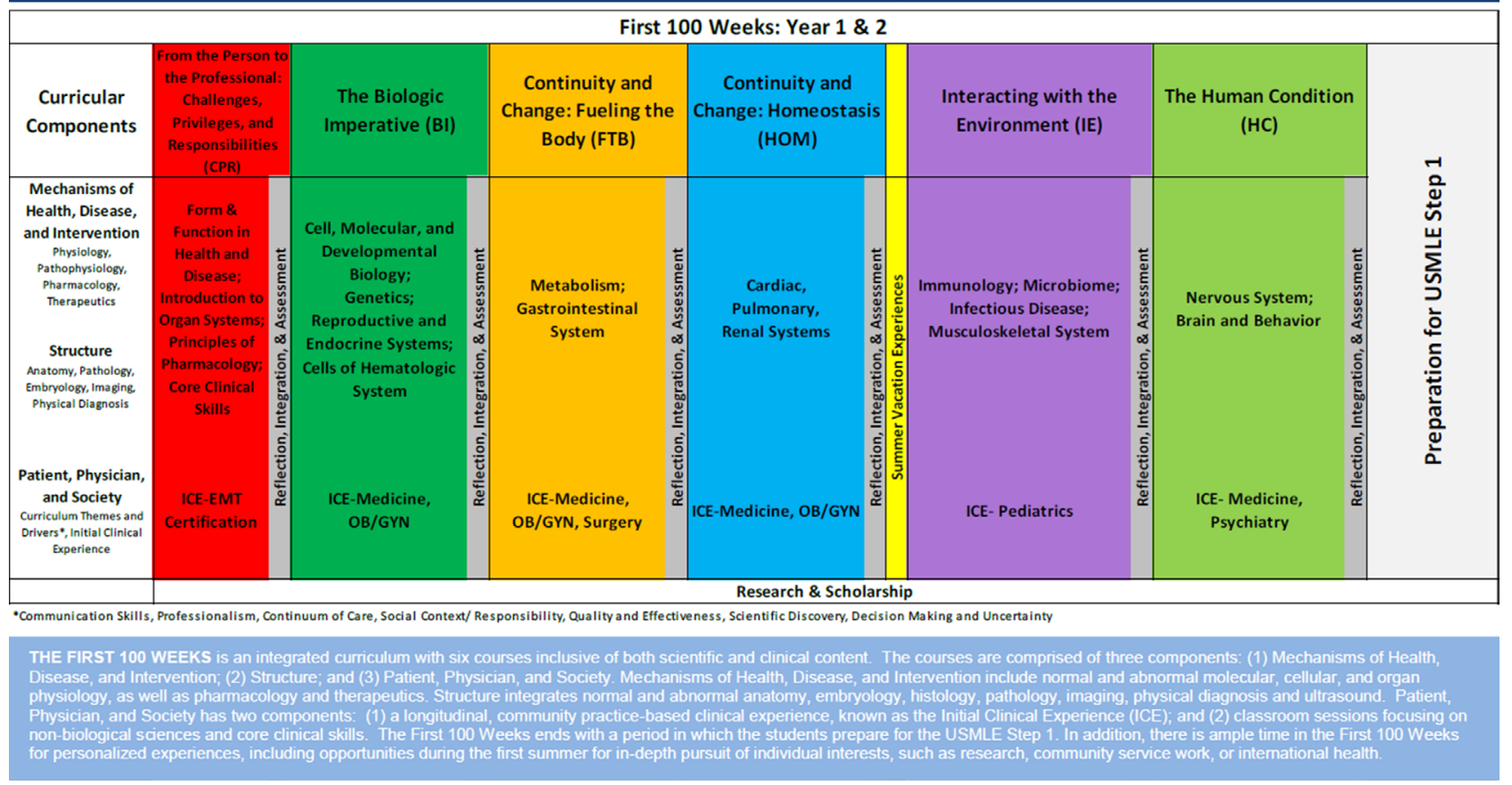

Figure I First 100 Weeks integrated courses.

Abbreviations: EMT, emergency medical technician; OB/GYN, obstetrics and gynecology; USMLE, United States Medical Licensing Examination. 
their peers with the knowledge that they would be expected to discuss the case in the debrief. A nurse confederate was present in each room to communicate laboratory results and carry out students' orders for the patient. Students were able to call for consultation; consultants were faculty who observed through a one-way window. Each simulation exercise lasted 8-10 minutes; immediately following the first simulation experience, the students were presented with another case in which those who observed the first case now actively participated, and vice versa. Cases reflected course content and enabled students to compare and contrast similarly appearing acute clinical presentations of illnesses with different underlying pathophysiologies. For example, following the Fueling the Body Course, which includes intermediary metabolism, both cases involved a patient with altered mental status; in one case, the patient had diabetic ketoacidosis, in the other, hyperosmolar, hyperglycemic nonketotic syndrome.

Following each pair of simulation exercises, each student team met with a physician and a basic scientist for a 40- to 50-minute biomedical and clinical science debrief utilizing questions from faculty guides. Basic and clinical science course directors created case-specific debrief questions together to illustrate the connections between these two disciplines. The facilitators' role was to prompt students to apply basic science principles to simulated clinical presentations, interpretation of diagnostic testing, and therapeutic management. Each debrief involved an active dialog between students and facilitators, who functioned as content experts to advance discussion only when needed.

All faculty who participated in simulation debriefs attended a 6-hour training course on advocacy and inquiry debrief techniques. ${ }^{7}$ In addition, faculty received a facilitator guide for each case in advance of the simulation and participated in a 30-minute faculty development session immediately prior to the simulation session to review the cases and debrief questions to help standardize the experience across simulation rooms.

Following each simulation with integrated debrief, students were asked to evaluate the experience by answering three questions, utilizing a 5-point Likert scale, relating to how useful the exercise was in demonstrating the clinical significance of basic science, demonstrating the role of basic science in patient care, and closing gaps in their knowledge (Table 1). Following the final two courses that were included in the pilot study, an open-ended question was added that asked students to describe how the experience helped them understand the clinical significance of basic sciences (Table 2). Content analysis of students' responses to this question was performed by five independent coders until thematic saturation was reached.

\section{Results}

Simulations with integrated basic and clinical science debriefs were experienced by first- and second-year medical students throughout one and a half years during this pilot study. When Likert score survey results were combined for all students, 95\% indicated that the debrief enabled them to understand the clinical significance of basic science content and $91 \%$ believed they had a better understanding of the role of basic science in patient care (Table 1).

After administering the Likert survey for six courses, and noting that the most highly rated question was, "the simulation experience enabled me to understand the clinical significance of basic science content," we sought to gain further insight. Therefore, following the final two courses of this pilot study, we asked students the open-ended question, "describe a way in which the simulation experience helped you understand the clinical significance of basic science." Four common themes emerged from content analysis of students' responses (Table 2). Representative comments, by theme, are given in the following sections.

Table I Students' evaluation of simulation with debrief experience

\begin{tabular}{llll}
\hline $\begin{array}{l}\text { Survey questions (rated on a 5-point Likert } \\
\text { scale with I = strongly disagree and }\end{array}$ & $\begin{array}{l}\text { Percentage of first-year } \\
\text { students (agree + strongly } \\
\text { agree } \pm \text { SD) }\end{array}$ & $\begin{array}{l}\text { Percentage of second-year } \\
\text { students (agree + strongly } \\
\text { agree } \pm \text { SD) }\end{array}$ & $\begin{array}{l}\text { Total no } \\
\text { of student } \\
\text { responses }\end{array}$ \\
\hline $\begin{array}{l}\text { The feedback provided in the debrief was helpful in } \\
\text { closing gaps in my knowledge }\end{array}$ & $88.6 \pm 4.7$ & $94.7 \pm 6.7$ \\
$\begin{array}{l}\text { The simulation exercise enabled me to understand } \\
\text { the clinical significance of basic science content }{ }^{\mathrm{a}}\end{array}$ & $93.8 \pm 2.9$ & $96.7 \pm 3.5$ \\
$\begin{array}{l}\text { After participating in the debrief discussion, I have } \\
\text { a better understanding of the role of basic }\end{array}$ & 92.8 & 90.4 \\
science in patient care $^{b}$ & & \\
\hline
\end{tabular}

Notes: ${ }^{\mathrm{V}} \mathrm{V}$ alues represent eight different simulation sessions. ${ }^{\mathrm{b}}$ This question was added most recently, so students were queried only at the conclusion of the most recent first- and second-year courses.

Abbreviation: SD, standard deviation. 
Table 2 Themes from students' responses to: “describe a way in which this experience helped you understand the clinical significance of basic science"

\begin{tabular}{lll}
\hline $\begin{array}{l}\text { Themed responses from } \\
\text { student comments }\end{array}$ & $\begin{array}{l}\text { First-year } \\
\text { student } \\
\text { responses } \\
\left(\mathbf{N}=\mathbf{7 9}^{\mathrm{a}}\right)\end{array}$ & $\begin{array}{l}\text { Second-year } \\
\text { student } \\
\text { responses } \\
\mathbf{( N = 7 6 )}\end{array}$ \\
\hline $\begin{array}{l}\text { Direct application of scientific } \\
\text { knowledge to diagnosis }\end{array}$ & 36 & 37 \\
$\begin{array}{l}\text { and treatment } \\
\text { Improving student knowledge }\end{array}$ & 20 & 16 \\
$\begin{array}{l}\text { Simulating real-world experience } \\
\text { Developing clinical reasoning }\end{array}$ & 14 & 11 \\
\hline
\end{tabular}

Note: aSome students provided more than one comment.

\section{Direct application of scientific knowledge to diagnosis and treatment}

- The difference in clinical presentations between the two sepsis patients made me think more critically about why two different bacteria would cause both similar and different physical signs and symptoms.

- The debrief was very helpful in consolidating the pharmacology, underlying pathophysiology and approach to two patients who presented similarly.

- The debrief discussion was great - we tied the sciences to the presentation of urinary tract infection, cleared up some confusion about why elderly patients do not necessarily mount a fever, and discussed why complement deficiency patients are particularly susceptible to Neisseria.

- It connected science that we knew from class to patient presentations which made us reevaluate our knowledge because we had gotten used to going from science to clinical presentation as opposed to clinical presentation to science.

\section{Developing clinical reasoning}

- Even though you learn the diseases in the classical scenario, it is unlikely the patient will present with a textbook clinical presentation.

- I better understood how laboratory data correlate with clinical presentation in the setting of shock.

- It was a good way for us to see the diseases we studied in school manifested in a clinical setting. It is one thing to read about them, but another to experience them in person. It was exciting to have a number of differentials for the patient and then slowly narrow down the list with further probing.

- It puts into perspective that differentials should be multisystemic and multifactorial, as it is easy to get locked into the mindset of whatever unit you are currently studying.

\section{Simulating real-world experiences}

- I believe it helps us use the tools we gain in case-based learning to identify issues of basic sciences within the case and apply these skills to treating the patient.

- It was very helpful to see topics we discussed extensively in case-based learning actually play out in the acute setting. Seeing patients with clinical presentations and trying to put the pieces together is very different from discussing those patients in the curriculum.

- Simulation made it easy to apply the things we were learning in the course.

- It was a great application of knowledge I learned in a textbook to a "real-life" situation.

- It forces you to take what you know, consolidate it, and apply it to a semi-real situation that you can remember and use to further your understanding.

\section{Discussion}

Gordon et $\mathrm{al}^{6}$ argue that simulation is an important enhancement to preclinical curricula as a way to complete basic science education. A survey by the Association of American Medical Colleges (AAMC) ${ }^{8}$ found that most schools that use simulation during the preclinical years do so for the purpose of teaching clinical skills, while very few schools report using small-group, high-fidelity simulation to teach basic science. ${ }^{6}$ Furthermore, few examples in the literature that evaluate simulation as a means to teach basic science focus on individual subject areas such as pharmacology, ${ }^{9}$ cardiac physiology, ${ }^{10-12}$ and neuroscience. ${ }^{13,14}$ These studies describe scenarios in which basic science principles are demonstrated clinically through the use of simulation, often while a large group of students watch rather than participate. ${ }^{9,13,14}$ While these studies reinforce simulation as an effective pedagogical tool, they do not directly address the potential role of simulation as a platform for learners to experience the integration of basic and clinical sciences.

Throughout the first 2 years of medical training, our students enroll in a single course at a time that incorporates physiology, pathophysiology, and therapeutics in a case-based curriculum aligned with weekly clinical experiences. This exposure to normal, abnormal, therapeutics, and clinical medicine creates an opportunity to harness this learning for the purpose of contextualizing the relevance of basic science in the clinical care of patients through simulation with an integrated debrief. Indeed, our first- and second-year students reported that integrating basic and clinical sciences into small-group simulation debriefs effectively contextualized the role of basic sciences in the clinical care of patients and helped close their knowledge gaps. 
Unlike previous studies, we examined the value of simulation in the context of an integrated curriculum which provides two unique opportunities: 1) it allows learners to synthesize content from multiple scientific disciplines and relate them to clinical medicine and 2) it allows learners to use their emerging clinical knowledge and skills as a platform for appreciating the clinical relevance of the basic sciences. Our approach places learners in simulations in which they must act to clinically diagnose and manage patients with conditions related to their coursework. Their clinical care of the patient is then deconstructed during the debrief. Basic science principles are applied to explain the patients' presentations and the rationales behind the appropriate diagnostic testing and pharmacologic management. Indeed, the majority of our students cited the direct application of basic science principles to diagnosis and treatment during the simulation and debrief experience as factors that helped them appreciate the clinical significance of their basic science knowledge. This is further demonstrated by the results of our inaugural AAMC Graduate Questionnaire in which the number of our students who strongly agreed that, "basic science coursework had sufficient illustrations of clinical relevance" was more than twice the national average.

\section{Limitations}

Limitations of our pilot study include variation in debrief content across facilitators, although this is minimized by the use of faculty guides. In addition, although students feel that this experience improves their understanding of the relevance of basic science in clinical medicine, we do not know if it actually improved their ability to use scientific principles to solve clinical problems. Our future work will focus on measuring the impact of our simulation and debrief approach on student application of biomedical science to clinical reasoning skills.

\section{Conclusion}

To our knowledge, this is the first description of the perceived value of a basic and clinical sciences debrief following high-fidelity, small-group simulation for first- and second-year medical students in an integrated curriculum. Experience with our medical students demonstrated that this is an effective pedagogy for building an appreciation of the clinical relevance of foundational biomedical sciences. Students reported that these sessions connected the basic to clinical sciences by allowing them to directly apply scientific knowledge to diagnosing and treating patients, develop clinical reasoning skills, and simulate real-world experiences. We view simulation linked to integrated biomedical and clinical science debrief as an emerging educational opportunity that can be utilized with early learners to facilitate their understanding of the application of basic science principles to patient care that may improve diagnostic and therapeutic decision making as well as clinical reasoning. We look forward to measuring outcomes in these areas as they relate to the simulation experiences we provide our students.

\section{Ethical statement}

All data utilized for this study came from students who gave their written informed consent to have their answers used after reading and agreeing to the following statement, "I voluntarily consent to participate in the Research Registry and therefore give permission for the educational data that has been or will be collected throughout my undergraduate experience at Hofstra Northwell School of Medicine to be included in the Registry." This study was submitted to the Hofstra Northwell School of Medicine's Institutional Review Board and was determined to be exempt from review.

\section{Acknowledgments}

The authors would like to acknowledge the contributions of the administrators, faculty, and staff at the Hofstra Northwell School of Medicine and the Northwell Health Center for Learning and Innovation who made the work described in this article possible.

\section{Disclosure}

The authors report no conflicts of interest in this work.

\section{References}

1. Kulasegaram KM, Martimianakis MA, Mylopoulos M, Whitehead CR, Woods NN. Cognition before curriculum: rethinking the integration of basic science and clinical learning. Acad Med. 2013;88(10): $1578-1585$.

2. Ginzburg S, Brenner J, Willey J. Integration: a strategy for turning knowledge into action. Med Sci Educ. 2015;25(4):533-543.

3. Cooke M, Irby DM, O'Brien BC. Educating Physicians: A Call for Reform of Medical School and Residency. Stanford, CA: Carnegie Foundation for the Advancement of Teaching; 2010.

4. Woods NN, Neville AJ, Levinson AJ, Howey EH, Oczkowski WJ, Norman GR. The value of basic science in clinical diagnosis. Acad Med. 2006;81(10 suppl):S124-S127.

5. Brauer DG, Ferguson KJ. The integrated curriculum in medical education: AMEE Guide No. 96. Med Teach. 2015;37(4):312-322.

6. Gordon JA, Hayden EM, Ahmed RA, Pawlowski JB, Khoury KN, Oriol NE. Early bedside care during preclinical medical education: can technology-enhanced patient simulation advance the Flexnerian ideal? Acad Med. 2010;85(2):370-377.

7. Rudolph JW, Simon R, Rivard P, Dufresne RL, Raemer DB. Debriefing with good judgment: combining rigorous feedback with genuine inquiry. Anesthesiol Clin. 2007;25(2):361-376. 
8. Passiment M, Sacks H, Huang G. Medical Simulation in Medical Education: Results of an AAMC Survey. Washington, DC: Association of American Medical College; 2011. Available from: https:// www.aamc.org/download/259760/data. Accessed September 23, 2016.

9. Via DK, Kyle RR, Trask JD, Shields CH, Mongan PD. Using highfidelity patient simulation and an advanced distance education network to teach pharmacology to second-year medical students. J Clin Anesth. 2004;16(2):144-151.

10. Kelsey R, Botello M, Millard B, Zimmerman J. An online heart simulator for augmenting first-year medical and dental education. Proc AMIA Symp. 2002;2002:370-374.
11. Gordon JA, Brown DF, Armstrong EG. Can a simulated critical care encounter accelerate basic science learning among preclinical medical students? A pilot study. Simul Healthc. 2006;1 Spec no:13-17.

12. Sheakley ML, Gilbert GE, Leighton K, Hall M, Callender D, Pederson D. A brief simulation intervention increasing basic science and clinical knowledge. Med Educ Online. 2016;21:30744.

13. Fitch MT. Using high-fidelity emergency simulation with large groups of preclinical medical students in a basic science course. Med Teach. 2007;29(2-3):261-263.

14. Heitz C, Brown A, Johnson JE, Fitch MT. Large group high-fidelity simulation enhances medical student learning. Med Teach. 2009; 31(5):e206-e210.

\section{Publish your work in this journal}

Advances in Medical Education and Practice is an international, peerreviewed, open access journal that aims to present and publish research on Medical Education covering medical, dental, nursing and allied health care professional education. The journal covers undergraduate education, postgraduate training and continuing medical education including emerging trends and innovative models linking education, research, and health care services. The manuscript management system is completely online and includes a very quick and fair peer-review system. Visit http://www.dovepress.com/testimonials.php to read rea quotes from published authors.

Submit your manuscript here: http://www.dovepress.com/advances-in-medical-education-and-practice-journal 